\title{
Earlier Is Better: Learning English in Saudi Arabia
}

\author{
Meshari A. Alsairi ${ }^{1,2}$ \\ ${ }^{1}$ School of Arts, Murray State University, Murray, United States of America \\ ${ }^{2}$ School of Arts, Law \& Social Sciences, Anglia Ruskin University, Cambridge, United Kingdom \\ Correspondence: Meshari Alsairi, Bisha, 61361, Saudi Arabia. Tel: 966-590-606-442. E-mail: \\ Malsairi1@gmail.com
}

Received: November 10, 2017 Accepted: December 14, 2017 Online Published: December 16, 2017

doi: 10.5539/elt.v11n1p141 URL: http://doi.org/10.5539/elt.v11n1p141

\begin{abstract}
Various studies have been carried out in order to find out the suitable age for foreign language acquisition. Every research study has had a different Critical Period (CP) and most of them have not been really close together in terms of years. Critical Period refers to the actual time frame during which foreign language acquisition should take place. The study at hand does not look at the actual age, but at theories about why there is an age. Age comes as a result of factors that urge one into learning a second foreign language. These factors are known as domains. Due to this fact this survey investigates why children should be taught a foreign language earlier as well as assessing their feelings about learning a new language (Li \& Schmitt, 2009).
\end{abstract}

Keywords: early, age, Saudi Arabia, teaching, English, acquisition

\section{Introduction}

Sociolinguistics say that early learners are better placed than adult learners since children learn faster than adults because their learning often goes hand in hand with physical actions. They are, therefore, availed with a concrete environment that they can relate their learning to. Thus, they have to comprehend the language in their play and school environments in order to be able to execute the required actions. Due to this fact, they are able to engage in communication outside of the classroom setting into an environment that is natural, informal, and relaxed. Meanwhile, adults tend to learn without physical responses which lessens the motivation to learn. At the end of the day, learning becomes routine-like and this eventually results in boredom (Hayes, 2006).

Some scholars like (Martin et al., 1988, Tomasello, 2000) argue that the critical time for language acquisition started from ages of 2 years to puberty. Before the age of two, it is impossible to learn because of different maturational problems such as the cognitive aspect of the brain not yet being developed. On the other side, after puberty it is more difficult to learn a foreign language because of a loss of cerebral plasticity which is a result of cerebral dominance due to lateralization of the language function. Basically, this means that the mind has physically and emotionally elasticized and matured and simply is not open to new things in the area of language (McKay, 2008).

In order to examine the reality of some of the above statements the researcher carried out a study at two Middle schools in Bisha city in Saudi Arabia. There were 33 participants aged between ages 11-14 years, all taking English as a foreign language (EFL). Five English language teachers were also interviewed who were currently teaching in high schools. Data was collected by the use of guided semi-structured interviews, questionnaires and observation. The collected data was coded and categorized into various categories, transcribed, translated, and then analyzed.

\subsection{Research Questions}

There was use of conceptualized research questions guided by a review of the literature from related past research. The research questions include;

1). Should learning begin at an early age?

2). What should any educational system consider before teaching a foreign language?

3). Is age a related factor for children studying in Saudi schools where acquisition of L2 is concerned?

4). What are the major differences between native speakers and early learners of L2?

5). What are the factors that prevented teaching English at an earlier age in Saudi Arabia? 
6). What are the students' and teachers' opinions about teaching earlier?

\section{Literature Review}

\subsection{Foreign Language Acquisition}

Foreign language acquisition is the process by which people learn a second, foreign language in addition to their native language. The Foreign language learned is normally referred to as target language and is abbreviated as SL2 or L2. The learning of foreign language (L2) may start as early as when one is in childhood, puberty, or later in life as an adult (American Community Survey, 2005). Although various writers and scholars have written on this topic, the researcher will examine a few of them and try to compare some of their findings.

Evidence has been given to support the view that children can learn a foreign language more easily than adults. Most of this evidence comes from observations made in studies on children with severe brain injury or skull trauma. According to these studies, children tend to relearn faster than their adult counterparts. One fairly recent study, carried out in the United States, backed up these findings. The study also found out that children learn faster and better than adults (American Community Survey, 2005).

In another study carried out on 71 Cuban immigrants who had been in the United States for about five years, it was discovered that the younger the immigrants were when they entered the country and began speaking English, the more similar their pronunciation was to that of native English speakers (American Community Survey, 2005). The findings of this study are backed up by a study conducted by Oyama (1976) on 60 Italian male immigrants as well as one conducted in Fathman (1975, reported in: American Community Survey, 2005). However, it is important to note that the latter studies focused more on accents and pronunciation than on the actual knowledge of the language; learning to speak without an accent is still learning how to speak ( $\mathrm{Li} \& \mathrm{Schmitt}, 2009$ ).

However, there are other theories that oppose this. Muhamadul (2010) came up with the Use It or Lose It theory that compares the brain to a muscle. The theory notes that the language learning "muscle" wastes away or degenerates after a graceful period of time without being used. Just as a muscle needs to be exercised to realize its full potential, the same applies to the language learning "muscle". However, this time period when the language learning muscle atrophies due to redundancy is never specifically known. Nonetheless, as long as one is learning a new language these language systems are always in use to accommodate language acquisition (Muhamadul, 2010).

The implication of Muhamadul's theory is that there is no particular age group that is better placed to learn a foreign language better or faster. The conditions are already inbuilt in the human brain and, as such, it is impossible to completely argue that children learn foreign languages faster than adults. Newport and Goldwosky (1993) also found the benefits of starting language acquisition younger in relation to this theory. Elman (1993) found evidence supporting his model, starting with limited memory that undergoes and experiences exponential growth as maturational change takes place (increases in mental capacity) (Bailey \& Richard, 1991).

One of the reasons I find this theory to be the one I agree with the most is the multiple times it has been tried and tested. Acquiring a language earlier boosts one's scope of interaction network. This is because one is in a position to interact and communicate with a wide coverage of people from different cultures, and different geopolitical and geographical backgrounds. Consequently, one is not limited to monolinguals. This has a tendency to enhance one's self-esteem and one's sense of belonging. At the same time, one's scope of employment becomes wider since communication is not limited to one's native language (Hartshorn et al., 2010).

Additionally, as one grows up his or her cognitive abilities are occupied and obstructed by numerous activities, issues, and responsibilities in life, unlike a child, who has no demanding responsibilities and can afford to be focused (American Community Survey, 2005). According to Bailey and Richard (1991), the loss of learning capabilities is evidence that there is an area in the brain whose function is to assist or hasten the language learning process. This disease is a clear indication that foreign language acquisition does not depend on the age of a person. Foreign language acquisition depends on the capabilities of the UG, a part of the brain responsible for delivering instructions on how language can be learned effectively.

Birdsong (2000) holds the opinion that 'Conscious Language Learning' requires error correction as well as rules in order for children to acquire the second language in the right manner for proper linguistic generalizations. Learning any foreign language when children are very small is very advantageous, as children pick up the nuances, phonetics, and words quite easily.

Suzuki (2008) uses the 'maladaptive gain of process capacity with maturation theory' to prove that as a person gets older, he will look at things from a different angle. Some of these points of view have a direct impact on 
learning and clearly show that as the individual grows, so will his ability to learn a foreign language. According to Saad (2004), the reason why it would appear that children learn fast is because of their ability to process information in a very short time. Adults take a longer time because of the fact that they have to think about, and try out, different scenarios. However, this does not mean that children have better language learning skills than adults. It is wrong to equate fast acquisition of language skills to a child's processing capacity (Manami, 2008).

As for the Asia-Pacific Region, (Nunan, 2003) recommended some actions when teaching English in public schools. First, he suggested reviewing the starting age and intensity of foreign language instruction, along with the articulation of a rationale for both. Second, to identify learners' needs to compare them with human resources and materials, and analyze the costs with benefits. Third, to investigate the curriculum's principles and their effectiveness in classrooms. Fourth, to study the teachers' post-experiences and their proficiency. Also, to review the curriculum's principles, how they serve the main goals, and how appropriate are they. Finally, in cases where English is introduced before L1 literacy is fully established, an investigation into the effect of the introduction of an L2 on L1 literacy development is recommended (Nunan, 2003).

This research study has served to shed light on our understanding of language acquisition involving both L1 and L2. From this study, learning the Second Language (L2) from the early years is much more beneficial to the child than learning it later in life. Nonetheless, learning of both native language and foreign language is influenced by language domains which are basically family, religion, friendship, education, employment, and politics. Saudi Arabia is not an exception since these domains shape one's language acquisition. Saudi Arabia's religion is Islam and $100 \%$ of its constitution is based on the Holy Quran (Religious book of the Muslims). The Quran is written in Arabic and states many times that Arabic is very important since it was written in it. Hence teaching religion in any other language does not find favor with Muslims as it is difficult to teach their religion in another foreign language (David, 2000).

Secondly, political factors play an important role in applying such a decision. From a political angle, we understand that the identity of a nation is based on their culture, customs, and traditions. It is quite impossible to teach one's own culture in another language. Hence just imparting the knowledge of English without teaching them about their own culture will impact on them in a negative way.

Another factor is linguistic; teaching and learning in one's own language is always much easier than trying to teach and learn facts and concepts in an alien language. There is always the possibility of misunderstanding important things as there may be interference from various linguistic factors. The recent studies couldn't ignore the possibility of some interference between two languages. For example, some research proved there is little code mixing between English and Chinese. Another example is from Korea where children are taught English from the third grade, and parents spend at least one third of their income on private lessons in order to teach their children English along with other subjects. Even though there are some negative effects on the learners' national identity and L1 literacy, these problems were hidden because of the explosive demands for English language.

There is also the aspect of family background. Most parents communicate to their children in Arabic. This is because the language is highly valued as it is both the official language and the national language of communication. Thus, the language is used in both formal and informal settings. Consequently, most of the learners do have a chance to have an extra input of the language outside of a classroom setting especially in public schools

Finally, the psychological factor is still an important factor. Teaching and learning a new language, if not done in the proper way, may affect children psychologically. If they are not capable of picking up the language in the right manner, it would bring down their self-confidence and self-esteem. There are many underlying factors that may lead children into having psychological problems later. If teachers are not well trained, their teaching skills may be poor, and, as a consequence, their students would automatically pick up the wrong usage of language and would face a lot of difficulty later on in life which could lead to other psychological problems.

\section{Research Methodology}

The research employed a survey design. This is because it was covering a relatively wide population. The study was carried out at two Middle schools in Bisha city whereby there were 33 participants aged between ages 11-14 years all taking English as a Foreign language (EFL). The mean age was thus 13.3 years. The questions were asked in Arabic since the students' proficiency in English is not enough to have them understand and express their answers. Then, their answers were translated into English in order to analyze the data. Five English language teachers were also interviewed who are currently teaching in middle schools.

Data was collected by using guided semi-structured interviews and questionnaires. These questions were given 
during classroom time and were sent to the two different schools via a web site called survey monkey. As for the teachers, their interviews were conducted by sending the questions electronically (that is, via e-mail) because of the time zone.

\section{Results and Discussion}

Data was analyzed both qualitatively and quantitatively. Descriptive analysis was used to analyze and present qualitative data and information. It was integrated with statistical analysis to give the survey a holistic approach. A mixed-model, repeated-measures analysis of variance (ANOVA) was computed using the statistical package for the social sciences. The level for the significance was calculated at 0.01 level.

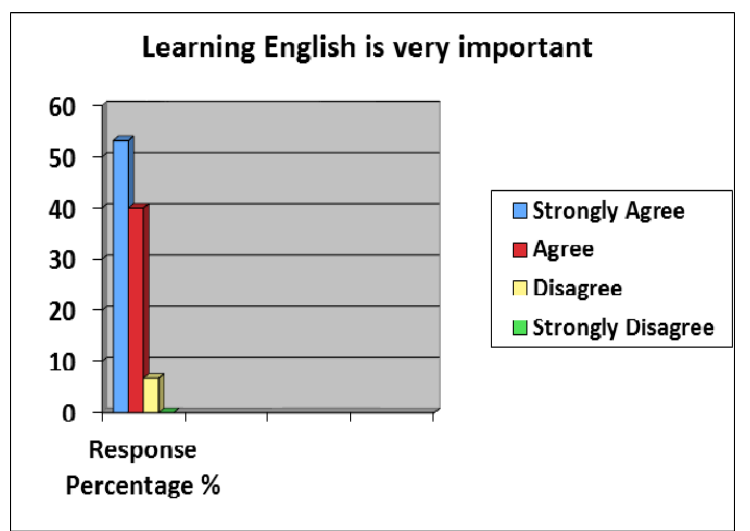

Figure 1. Students responses to how important is English

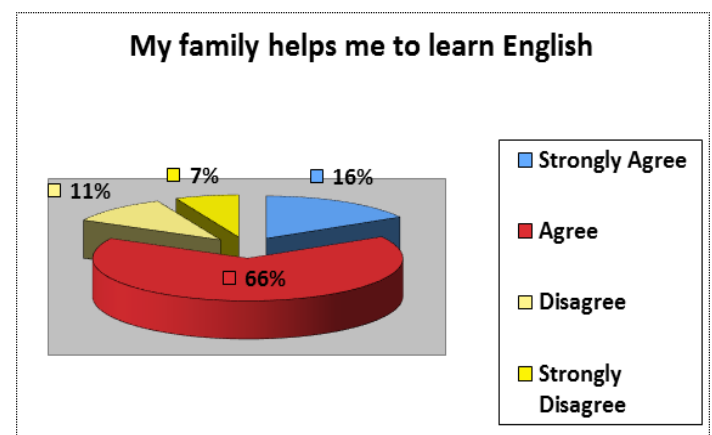

Figure 3. Students responses to their families help in learning English

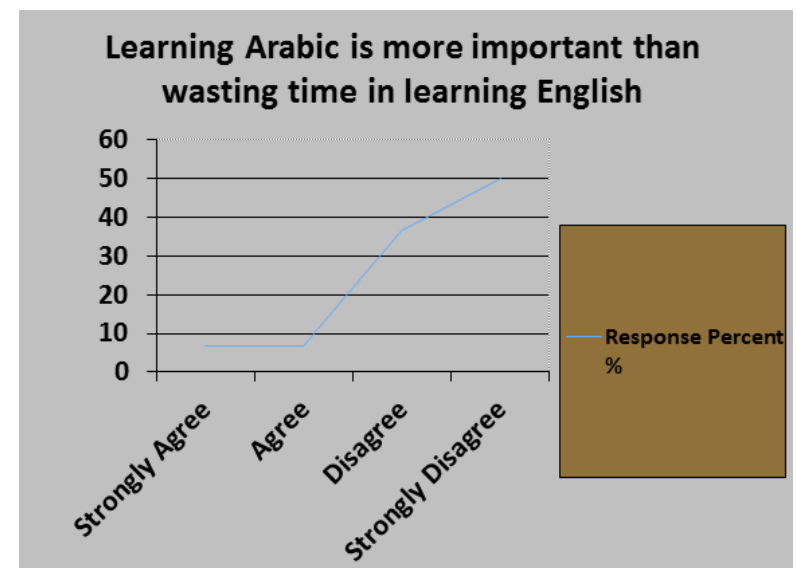

Figure 5. Studenrts responses to learning Arabic

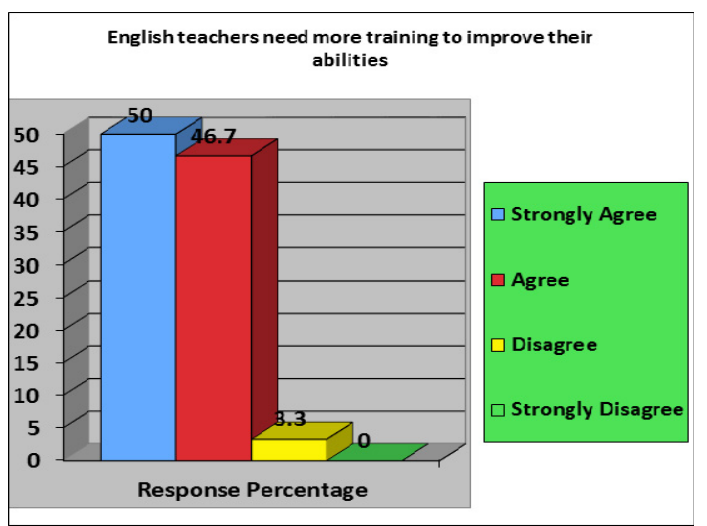

Figure 2. Students responses to English teachers abilities

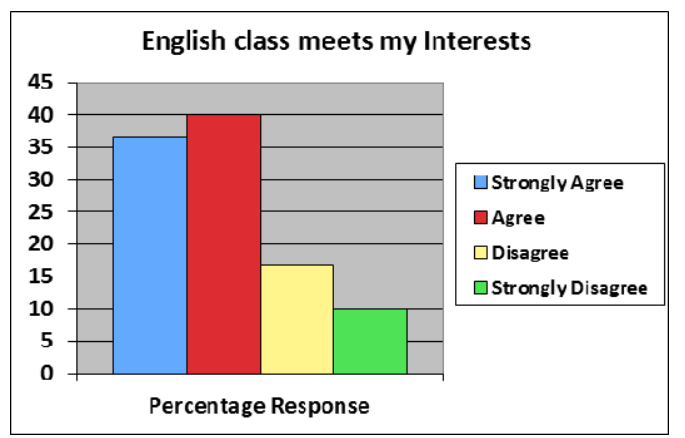

Figure 4. Students responses to English classes

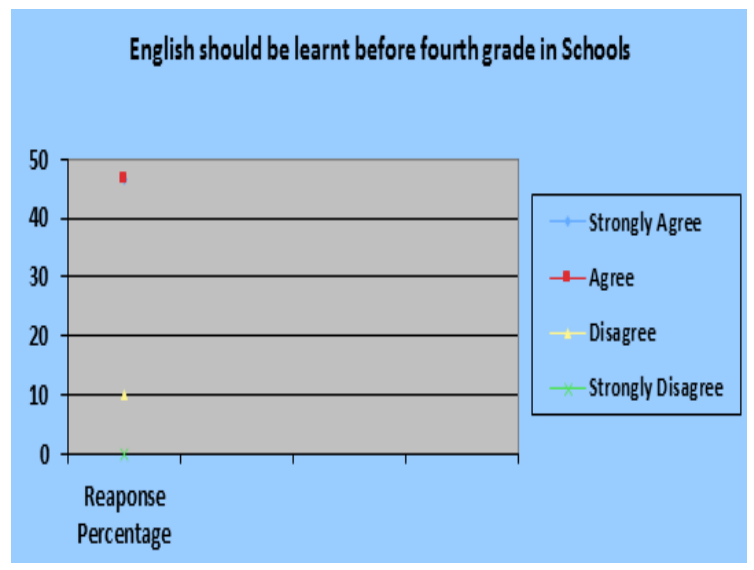

Figure 6. Students responses to when they should learn English 


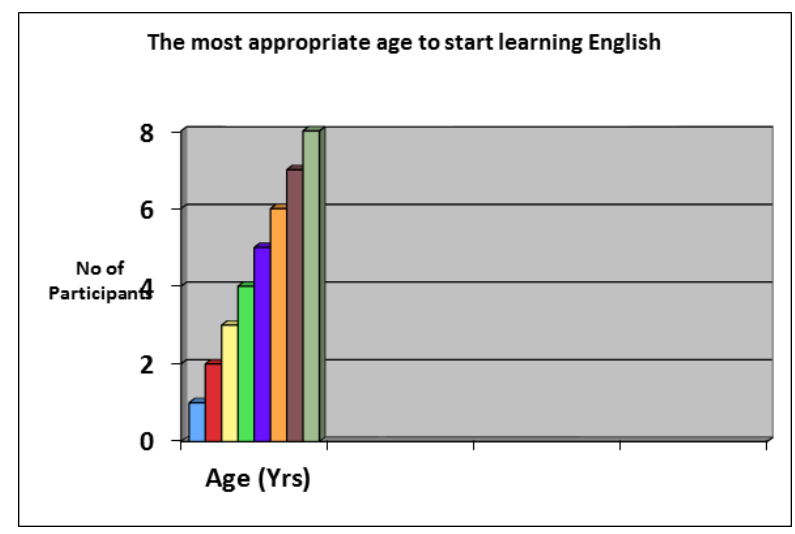

Figure 7. Students responses to appropriate age to learn English

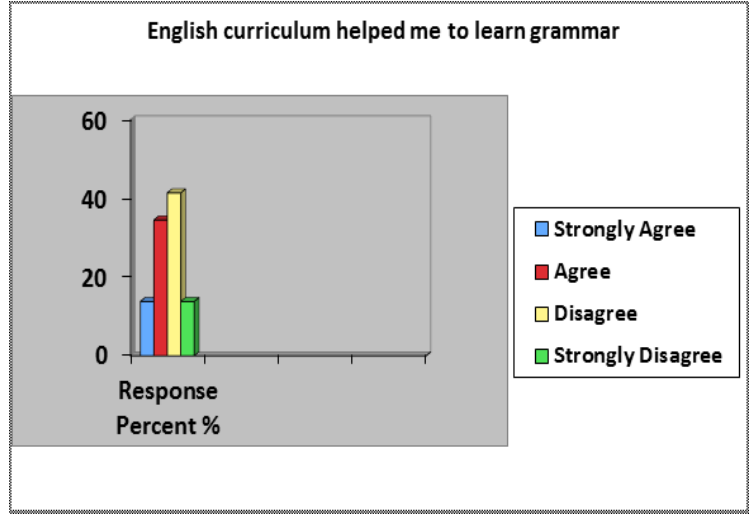

Figure 8. Students responses to the effectiveness of English curriculum

The main standard deviation was $0.01 .93 \%$ of the participants said that they perceived English as a very crucial language to pursue. The $7 \%$ who felt otherwise might have been due to lack of motivation from their homes, dull classroom experiences, or influence from their peers.

$97 \%$ of the participants said that their teachers needed more training to improve their skills. This may lead to another trust problem between students and teachers since they see their teachers as incapable of teaching adequately.

Table 1. Responses to the statement "We should have more than four English periods per week in schools"

\begin{tabular}{lll}
\hline & Response Percent \% & Response Count \\
\hline Strongly Agree & 53.3 & 16 \\
Agree & 33.3 & 10 \\
Disagree & 6.7 & 2 \\
Strongly Disagree & 6.7 & 2 \\
\hline
\end{tabular}

Responses to the statement "We should have more than four English periods per week in schools". The main standard deviation was $87 \%$ of the participants said that they preferred to have more time for English acquisition. These numbers show the evidence of their desire to learn English. Also, this shows that the time is not enough to acquire new language.

It was found that the family domain played a crucial role in the acquisition of English as a foreign language. 83\% of students said that they received support from their families. This is one of the most important questions in the survey because it shows how the families feel about teaching their children a new language. This can also reduce the limitation of this study since it doesn't have a designed questionnaire for parents.

$77 \%$ of the participants under the survey study admitted that English acquisition met their interests. The majority of the class seemed to enjoy their learning process.

Table 2. Responses to the statement "Schools have labs that help to learn English"

\begin{tabular}{lll}
\hline & Response Percent \% & Response Count \\
\hline Strongly Agree & 30.0 & 9 \\
Agree & 63.3 & 19 \\
Disagree & 3.3 & 1 \\
Strongly Disagree & 3.3 & 1 \\
\hline
\end{tabular}

Responses to the statement "Schools have labs that help to learn English". 
$87 \%$ of the participants agreed that the pursuit of English was not waste of time. Nevertheless $13 \%$ admitted that they felt learning of English was a waste of time. This could have been attributed to the value that is placed on Arabic language. Also, there could have been a lack of motivation, perhaps from peers, and/or a passive and non-conducive classroom atmosphere.

It was observed that learners who had started their learning as early as the age of four had pronunciations that were close to the English natives. Also, they were more fluent and had attained a higher English proficiency in terms of reading, writing, spelling, and speaking. Parents whose children started learning English as early as two years said that their children were successful in the acquisition of both English and Arabic.

Basically, English has not been embraced a lot in Saudi Arabia. This is basically the case because Arabic is the official and national language of communication. Documents, literature, and government offices are run in Arabic. This also applies to informal set ups like the mosques. This factor slows early acquisition of English in the country.

The teachers' interviews indicated that teaching at an early age helps learners learn more smoothly than later in life. However, learning English at this level has not yet been realized since parents and educators are apprehensive to incorporate English teaching at primary schools. Nonetheless, a compromise has been offered, which ended up teaching English at the final level of primary school, $6^{\text {th }}$ grade.

93\% of the participants felt that they should learn English from a tender age. During the interviews, when interrogated further, they kept on saying that they perceived that the acquisition of foreign language is easier for children as compared to adults.

Table 3. Responses to the statement "Learning English has bad influence on our Arabic language"

\begin{tabular}{lll}
\hline & Response Percent \% & Response Count \\
\hline Strongly Agree & 6.7 & 2 \\
Agree & 0.0 & 0 \\
Disagree & 53.3 & 16 \\
Strongly Disagree & 40.0 & 12 \\
\hline
\end{tabular}

Responses to the statement "Learning English has bad influence on our Arabic language". 7\% of the participants said that learning English has a bad influence on their Arabic language, yet 93\% said otherwise. Those teachers have children and therefore have dual roles, both teachers and parents. So, the majority said there is no interference between the two languages and they completely support teaching English early.

\section{Conclusion}

Acquisition of a foreign language yields better results when begun in childhood. Teachers should help non-natives by provision of activities that engage learners in group interactions. There should be a conducive environment for learning, such as positive reinforcement through appreciation. The government should ensure that there are enough resources, such as text books, and should sponsor English teachers for higher education for advancement of the language. Due to modernization and the advancement of science and technology, very orthodox and rigid educational systems do not favor the community. In order to avoid fear of interference regarding L2 learning, schools in Arabia can focus attention of L1 learning during the first 3 years of the curriculum, after which the two languages can be learned concurrently. There should also be ample time allocation for English language acquisition in order to realize the full benefits articulated in the English curriculum.

\section{Limitations of the Study and Pedagogical Suggestions}

The study took a short duration of time. A longitudinal survey should be carried out to give a more detailed report. Moreover, I did not look into the effects of many known factors on individual learners' L2 proficiency: teachers' instruction and feedback, educational and socio-cultural backgrounds, gender, age, goals, and motivation. Another shortcoming experienced was that it was not possible to contact the key officials in the ministry of education. However, the data was able to be collected from other alternative sources in the ministry such as teachers.

The teachers really appreciate the importance of foreign languages, especially English. Despite this view they are 
likely to be affected because most of them got their education through the Arabic language. So, most of them are not okay with the English language and can not efficiently handle it. In reaction to this, they are requesting an implementation that would allow them to catch up with others and will not cast them away from the system.

The Educational Ministry should also provide various English materials in schools and encourage teachers to use CALL in their lessons to cover the lack of time in the classes. The teacher also should consider giving extra classes to students and offer some activities outside the classroom since their students show great interest in learning a new language.

Another suggestion is that English language should be used as the language of communication in the lessons. This will help reduce the teaching of abstract grammar. The curriculum should also be designed with more sources and the use of modern materials such as electronic lessons to help students learn English in a shorter time. The curriculum can also recommend extra-curricular English activities, since the class time is limited and a step has to be made very fast concerning the learning of the English language. Finally, the teachers should focus more on their language proficiency since they themselves learned English late and by old methods, and also since Saudi Arabia doesn't have a TESOL organization to help them to improve their teaching.

\section{References}

Arturo, E. H., \& Ping, L. (2007). Age of Acquisition: It's Neural and Computational Mechanisms, Psychological Bulletin, 133(4), 638-650.

American Community Survey. (2005). Language Spread and Language Policy Issues,Implications and Case Studies. Washington DC: Georgetown University Press.

Choi, Mc Donough \& Bowerman (1999). Early Sensitivity to Language - Specific Spatial Categories in English and Korean. Cognitive Development, 14, 241-268.

Christian Abello- Contesse. (2008). Age and the Critical period Hypothesis. ELT Journal, 63(2).

David, M. S., \& Zsolt, L. (1995). The Age Factor in Second Language Acquisition. Multilingual Matters, 160.

Daniela, P. (1998). The Bilingual Brain. Proficiency and age of acquisition of the second language, 121, 1841-1852.

Giesela, J., \& Akiko, F. (2007). Acquisition of English Grammatical Morphology by Native Mandarin Speaking Children and Adolescents. Age-related differences. Journal of Speech language and Hearing research, 50, 1280-1299.

James, E. F., \& Robert, P. (1981). Language and Speech. Cross- language Phonetic Interference: Arabic to English, 24.

Jenifer Larson-Hall. (2007). Weighing the benefits of studying a foreign language at a younger starting age in a minimal input situation, Second Language Research, 24(1), 35-63.

Martin, E., Kikinis, R., Zuerrer, M., Boesch, C., Briner, J., Kewitz, G., \& Kaelin, P. (1988). Developmental stages of human brain: an MR study. Journal of Computer Assisted Tomography, 12, 917-22.

Muñoz, C. (2006b). The effects of age on foreign language learning: The BAF project. In C. Muñoz (Ed.), Age and the Rate of Foreign Language Learning (pp. 1-40). Clevedon: Multilingual Matters.

Muhamadul, B. H. Y. (2010). A Wave of Psychological forces in Second Language learning: An Arabic Experience at IIUM. Journal of U.S - China Public Administration, 7(7).

Myra, A. F., \& Cheryl, G. (2008). Experimental Aging Research, 34, 297-322.

Nunan, D. (2003). The impact of english as a global language on educational policies and practices in the asia-pacific region. 37(4), 25.

Rima, S. S. (2004). Early Childhood: Characteristics and Needs. Twelfth annual meeting of the Saudi Society for Educational and Psychological Sciences.

Sieneke, G., \& Kees, de B. (2010). Impact of early English language teaching on L1 and L2 development in children in Dutch Schools. International Journal on Bilingualism, 14(3), 289-302.

Stephen, D. K. (1981). Second Language Acquisition and Second Language Learning. The Center for Language and Linguistics, Pergamon Press Inc.

Susan, B. G. (2003). Qatar reshapes its Schools. Putting English over Islam.Washington Post Foreign Service.

Suzuki, M. (2008). Japanese Learners' Self Revisions and Peer Revisions Of Their Written Compositions in 
English. Dokkyo University. Soka, Japan.

Tomasello, M. (2000). Acquiring syntax is not what you think. In D. V. M, Bishop, \& L. B. Leonard (Eds). Speech and Language Impairments in Children: Causes, Characteristics, Intervention, and Outcome. Hove: Psychology Press.

\section{Appendix A}

Dear participants,

My name is Meshari Alsairi, a student at Murray State University. I'm carrying out a study to investigate learning new language in Saudi Arabia.

I need information as required by each of the following questions. Answer the questions as honestly as possible. Your cooperation will be highly appreciated. All information will be treated with strict confidentiality.

Thank you.

Meshari Alsairi

malsairi@gmail.com

- $\quad$ Section A

- Choose the correct response for each statement:

\begin{tabular}{|l|l|l|l|l|}
\hline The Statement & $\begin{array}{l}\text { Strongly } \\
\text { agree }\end{array}$ & Agree & Disagree & $\begin{array}{l}\text { Strongly } \\
\text { Disagree }\end{array}$ \\
\hline $\begin{array}{l}\text { 1- learning a new language has bad affects on the first } \\
\text { language. }\end{array}$ & & & & \\
\hline 2- We should learn English before fourth grade in Schools & & & & \\
\hline $\begin{array}{l}\text { 3- We should have more than four English periods per week } \\
\text { in schools }\end{array}$ & & & & \\
\hline 4- My family helps me to learn English & & & & \\
\hline 5- Learning English is very important & & & \\
\hline $\begin{array}{l}\text { 6- English teachers need more trainings to improve their } \\
\text { abilities }\end{array}$ & & & & \\
\hline 7- Schools have labs that help to learn English & & & \\
\hline 8- English curriculum helped me to learn grammar & & & \\
\hline $\begin{array}{l}\text { 9- English curriculum helped me to improve my reading } \\
\text { and writing }\end{array}$ & & & & \\
\hline $\begin{array}{l}\text { 10- I feel curriculum of English helps me to communicate } \\
\text { with people in English }\end{array}$ & & & & \\
\hline $\begin{array}{l}\text { 11- I feel learning Arabic is more important than wasting } \\
\text { time in learning English }\end{array}$ & & & & \\
\hline 12- English Class meets my interests & & & \\
\hline $\begin{array}{l}\text { 13- I noticed that my English language started to improve } \\
\text { fast from learning in schools }\end{array}$ & & & & \\
\hline
\end{tabular}


Answer the following questions:

1- What is the most appropriate age to start learning English?

2- How many periods you should take in order to learn English?

3- What are your suggestions or comments about learning English in general

Your General Information
I am ............. Years old. I am in the........ level.

Thank You

\section{Appendix B}

Teachers' Interview

Please explain each question to the best of your knowledge.

1. In your opinion, what is the suitable age for teaching English in Saudi Arabia?

2. What are the difficulties that face English teachers in Saudi Arabia?

3. Do you think there is interference might happen between L1 and L2 when we try teaching children in early age?

4. Arabic language is considered as precious value in Saudi society, how can the education system keep this value and teach English in the same time?

5. Do you think English curriculum helps students and teachers in learning process?

6. How do you see student's perspective to learning English?

7. What is parents' position in learning new language? Are they cooperative, neutral, or against the idea?

8. How are English teachers training? Do you think they are qualified to deal with such difficulties?

9. Students in sixth grade take two English periods weekly and one year later they take four until they finish high school. How do you see students' exposure to new language especially with the lack of English usage in the Saudi environment?

10. As a teacher and a parent, when you are going to teach your children new language and why?

\section{Copyrights}

Copyright for this article is retained by the author(s), with first publication rights granted to the journal.

This is an open-access article distributed under the terms and conditions of the Creative Commons Attribution license (http://creativecommons.org/licenses/by/4.0/). 